\title{
ANALYSIS OF FAILURE DETECTION AND VISIBILITY CRITERIA IN PANTOGRAPH-CATENARY INTERACTION
}

\author{
Sakir Parlakyıldız ${ }^{1,1}$, Muhsin Tunay Gencoglu ${ }^{2,2}$, and Mehmet Sait Cengiz ${ }^{1,3}$ \\ ${ }^{1}$ Department of Technical Vocational School, Bitlis Eren University, Turkey \\ ${ }^{2}$ Department of Electrical Electronics Engineering, Firat University, Turkey \\ E-mails: ${ }^{1}$ sparlakyildiz@beu.edu.tr, ${ }^{2}$ mtgencoglu@firat.edu.tr, ${ }^{3}$ msaitcengiz@gmail.com
}

\begin{abstract}
S
The main purpose of new studies investigating pantograph catenary interaction in electric rail systems is to detect malfunctions. In the pantograph catenary interaction studies, cameras with non-contact error detection methods are used extensively in the literature. However, none of these studies analyse lighting conditions that improve visual function for cameras. The main subject of this study is to increase the visibility of cameras used in railway systems. In this context, adequate illuminance of the test environment is one of the most important parameters that affect the failure detection success. With optimal lighting, the rate of fault detection increases. For this purpose, a camera, and a LED luminaire $18 \mathrm{~W}$ was placed on a wagon, one of the electric rail system elements. This study considered CIE140-2019 ( $2^{\text {nd }}$ edition) standards. Thanks to the lighting made, it is easier for cameras to detect faults in the electric trains on the move. As a result, in scientific studies, especially in rail systems, the lighting of mobile test environments, such as pantograph-catenary, should be optimal. In environments where visibility conditions improve, the rate of fault detection increases.
\end{abstract}

Keywords: rail system lighting, pantograph-catenary interaction, fault detection visibility, luminance, illuminance

\section{INTRODUCTION}

As in all areas, the biggest need for transportation is energy. Energy consumption is increasing day by day due to the needs of modern life, the increasing competition environment, and cultural and social developments. The area where electric energy is used in transportation systems is electric rail systems. Demand for railway transportation is increasing. The energy required to move the train comes from the power line. For the rail system vehicle to be continuously energized, there must be constant contact between the power line and the pantograph. Even a short-term non-contact between the pantograph and the catenary negatively affects the rail system vehicle and the electronic systems inside it. Therefore, the interaction between the pantograph and the catenary should be tested dynamically and statically at certain intervals. In order to detect malfunctions in the dynamic interaction of pantograph-catenary on the travel wire, the force applied by the pantograph mounted on the rail system vehicles and providing the necessary energy to the train set is measured. If this force is applied more than desired, it causes breaks due to the force of the electric line. If the applied force is small, the electric train causes arcing and mechanical damage to the pantograph while driving. Accelerometer sensor, load cell sensor and encoder or GPS system are required to perform these tests [1-6]. In this study, the lighting conditions of a recording system with a LED lamp and a camera mounted on a wagon using in an electric rail system were analysed. 


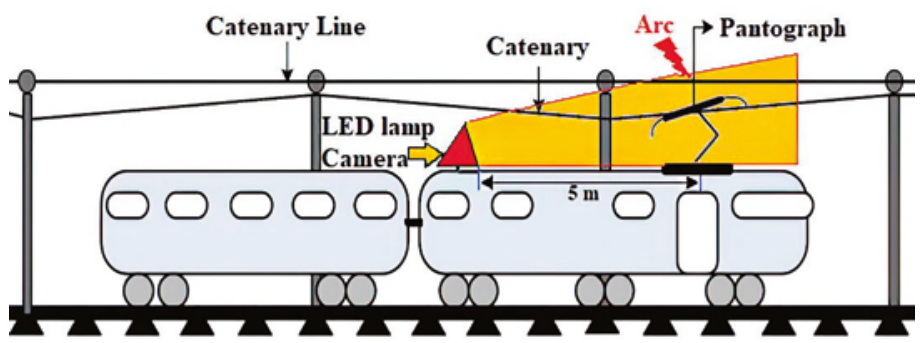

Fig. 1. System that records and illuminates the pantograph catenary image [1-4]

\section{LIGHTING AREA}

Electric rail systems have been used in transport for many years. The most important element in electric rail systems is the pantograph and the catenary. Compatibility between the pantograph and the catenary is one of the most important issues in these systems. The pantograph is a movable and catenary fixed element. These two elements are in contact with each other, and movement is provided in electric rail systems. Therefore, the pantograph-catenary interaction that moves and contacts each other increases the number of failures [1-6].

Current in the pantograph is the primary source of failure in electric rail systems. The pantograph is located on the roof of the train and collects current from the upper catenary line. The catenary line is fixed to poles with support points at regular intervals along the railway line [7-9]. When the train is moving, the pantograph moves along the catenary line to support energy continuity. When the speed in the electric rail systems increases, vibrations occur in the catenary line. This disrupts the interaction between the pantograph and the catenary. These vibrations negatively affect the contact between the pantograph and the catenary. Since the contact between the pantograph and the catenary is interrupted by electrical contact, wear and arc occur. In electric rail systems, elements other than pantograph-catenary are advantageous in terms of maintenance factor $[7,8]$. So, they usually do not cause malfunctions. Therefore, care factor multipliers are high. The source of the malfunction is the pantograph catenary interaction elements. For this purpose, many studies are conducted in scientific studies that study the pantograph catenary interaction. However, the lighting conditions are not taken into consideration in recordings made with the camera in fault detection studies. Therefore, sufficient success is not achieved in fault detection. This study provides appropriate lighting for camera recording during a moving train. In this way, it has been un- derstood that the camera can record (for the lighting class $M 2,50 \mathrm{~km} / \mathrm{h}<$ speed $<90 \mathrm{~km} / \mathrm{h}$ ) more accurately when the illuminance levels and luminance are selected appropriately [9, 10]. Fig. 1 shows the system that records and illuminates the pantograph catenary image.

\subsection{Methods}

In electric rail transport systems, arc and abrasions occur due to the horizontal movement-balance of the pantograph and the contact force applied by the pantograph to the catenary. If the interaction between the pantograph and the catenary is inappropriate, the contact is cut. Therefore, the train is de-energized. The vibrations of the contact wire and external effects cause malfunctions in the rail systems. It is important that periodic monitoring, fault detection, and necessary maintenance can be predicted in railway systems. Monthly checks of railway systems focus on two important points. These are the monitoring of the rail profile and the catenary line. Accidents are determined in advance by examining factors that cause accidents, such as abrasion, breaking, bending, catenary line stretching, contact condition, compatibility of catenary line, and pantograph axis of rails. Image processing based contactless methods have been developed using cameras to diagnose these faults. Nowadays, contactless condition monitoring methods are more preferred. With the cameras used in these methods, the railway line is monitored without contact, and the image processing algorithms developed, and malfunctions in the railway line are detected. Such methods are efficient methods that work faster, reducing workload.

- Various mathematical methods have been analysed using cameras to detect components and faults in rail systems. These methods are support vector machine, Gabor filter, basic image processing methods, deep learning, binary pattern matching base, wavelet transform, template matching, Hough trans- 


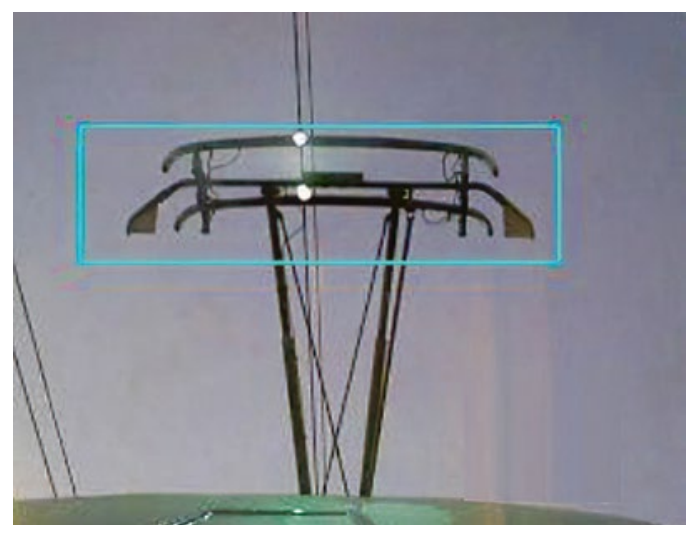

Fig. 2. Pantograph-catenary arc failure in non-illuminated environment [1-5]

form, Sobel edge extraction, line segment detector, and batch algorithm conversion techniques [11-24].

- Images recorded with the camera were analysed by the black tree conversion technique to detect the rail faults with loose connections [25].

- To detect defects in the railway fasteners, analysis was done using machine vision methods using a camera [26-31].

- An analysis was conducted with basic image processing methods using camera for scissors detection malfunctions [32-34].

- HSV colour conversion, masking, edge extraction, and basic image processing methods were analysed using the camera for the detection of rail line tracking [35].

- Using the camera for surface detection; visual based methods, Haar-like method, Otsu method, machine vision method, adaptive background extraction, image segmentation, deep learning, deep convolutional neural network, gaussian filter, edge extraction methods, and object recognition techniques were analysed [36-47].

Although each study uses different methods, the common point of these studies is the use of camera images. However, none of these studies did not consider the vision conditions of the camera. In this case, troubleshooting has become difficult. Optimal lighting should be done to increase the rate of fault detection.

The most important problem here is that the camera cannot record clearly in any conditions. For the camera to record clear images in day or night conditions, the criteria specified in CIE road standards should in terms of illuminance level and luminance values. Because trains running on rail systems should be evaluated as road vehicles in motion. Any arc or malfunction between the pantograph and the

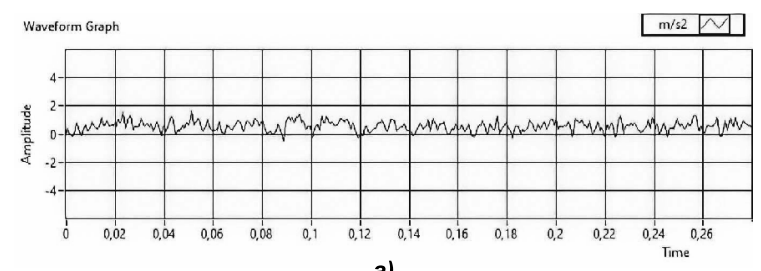

a)

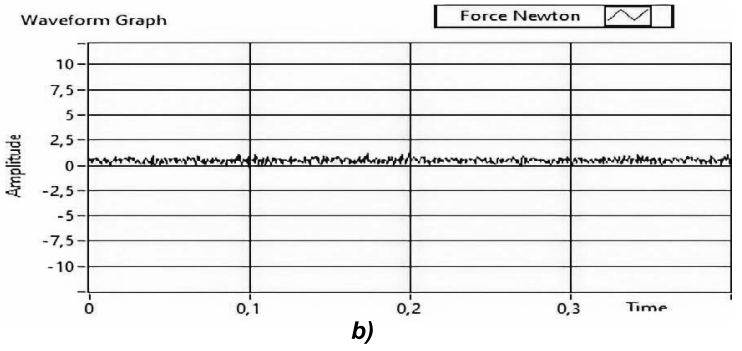

Fig. 3. When the electric train is stationary, signals from the accelerometer $(a)$ and signals from the force sensor $(b)$

catenary during the movement of the electric train is recorded by the camera. For the camera to clearly detect this fault, parameters such as speed, surface type, reflection coefficient, luminous flux, distance, and maintenance factor must follow CIE-140 standards. So, a train in railway systems is like a vehicle on a highway $[48,49]$. There are many studies in the literature that have been done using a fault detection camera. However, in no study was the visibility of test runs evaluated in terms of lighting. Arc and malfunctions caused by poor visual conditions are sometimes not detected by the camera. In other words, in experimental studies (if it is specific to each experiment), the most important parameters that affect visibility are optimal illuminance level and luminance values [50-52]. Fig. 2 shows the state of the pantograph-catenary arc failure in the non-illuminated environment.

\subsection{Condition Monitoring and Fault Detection}

Many contact and contactless methods have been developed for monitoring the components that make up the railway line. When reviewing current research in the literature, it is clear that non-contact methods are more profitable. Image processing-based methods are used to detect malfunctions in rail components and rail surfaces. Images are taken from the railway system via a camera. Status monitoring and diagnostics are performed on the acquired images using some image processing techniques. Experimental installations for the developing image processing-based methods are quite simple and do not require large costs. As a result of the 

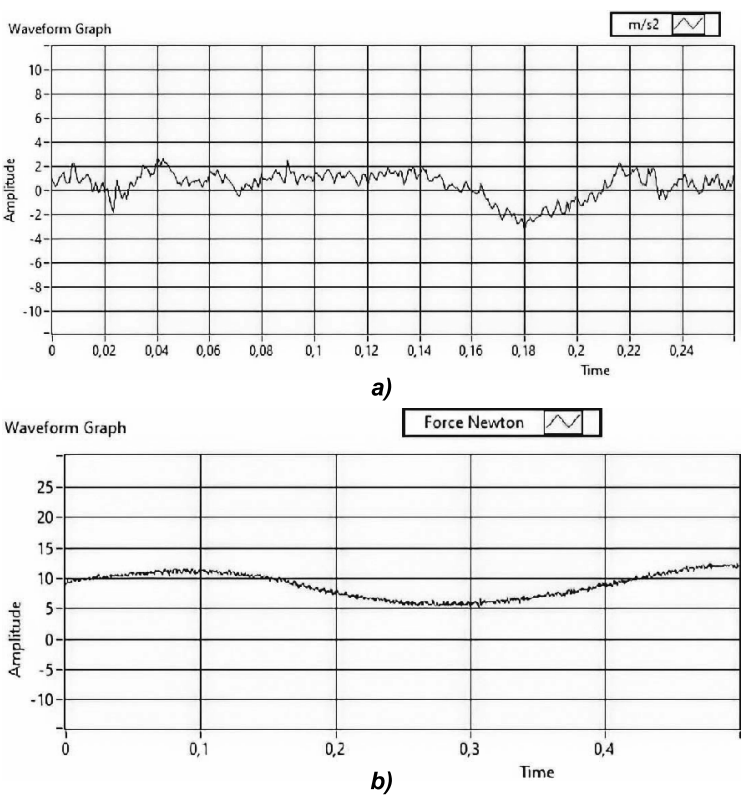

Fig. 4. Electric train in motion (no fault), signals from the accelerometer $(a)$ and signals from the force sensor $(b)$

measurements conducted physically in the test environment, the signals received from the electric train are shown in Figs. 3-5.

In Fig. 3, when the electric train is stationary, signals from the accelerometer and signals from the force sensor are shown. In Fig. 4, the electric train is in motion (no malfunction), signals from the accelerometer and signals from the force sensor are shown. In Fig. 5, the electric train is in motion (at the time of failure), signals from the accelerometer and signals from the force sensor are shown.

The moment when the visual conditions are the most important for the camera is the breakdown moment in Fig. 5. During the malfunction, the sensors detect vibration because they measure physically. That is, sensors detect the malfunction, but if the vision conditions are not good, the camera cannot detect the malfunction. The accelerometer and force sensors detected this malfunction. Therefore, vision conditions need to be improved. If the camera recording the fault clearly detects it, the fault
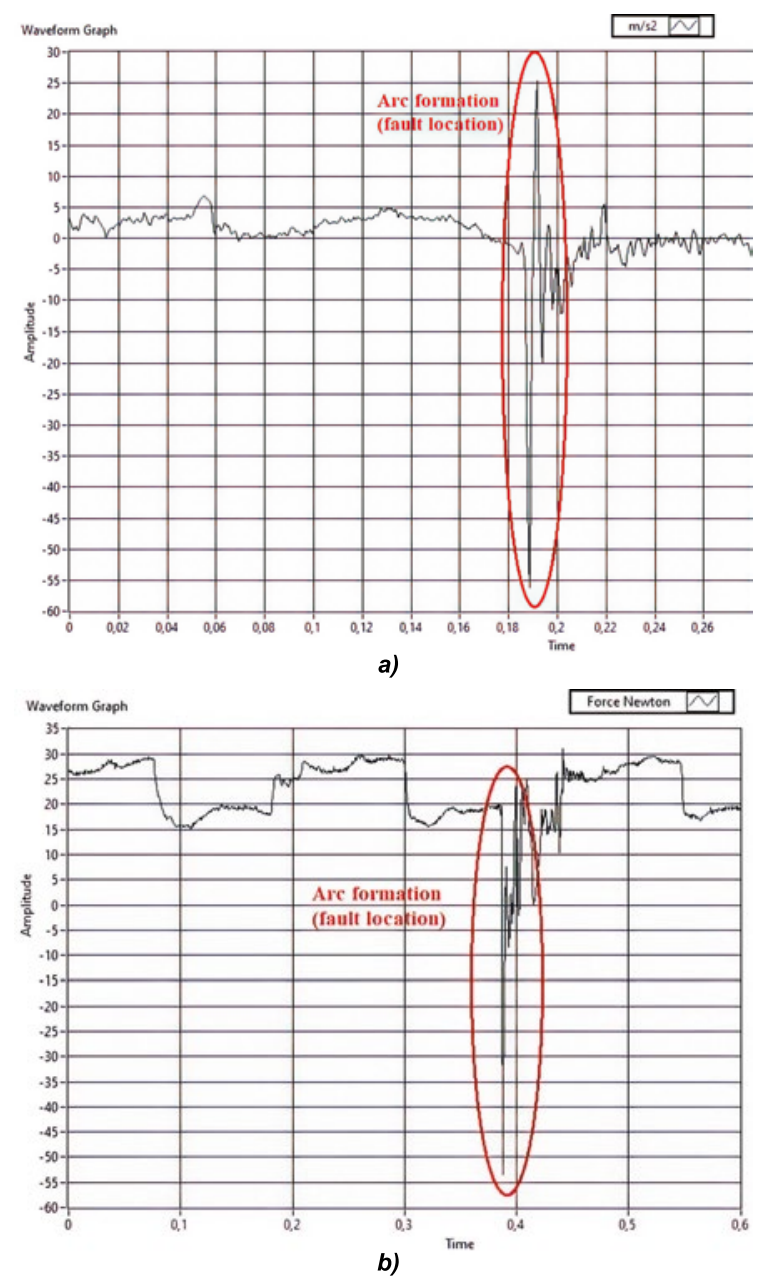

Fig. 5. Electric train in motion (at the time of failure), signals from the accelerometer $(a)$ and signals from the force sensor $(b)$

can be detected. If the lighting conditions are not suitable, some faults are not visible. However, the sensors that make physical measurements verify the fault information. Therefore, the lighting criteria cannot be neglected.

\section{AREA LIGHTING DESIGN}

Point lighting calculation method was used in area lighting calculation. In this method, the area

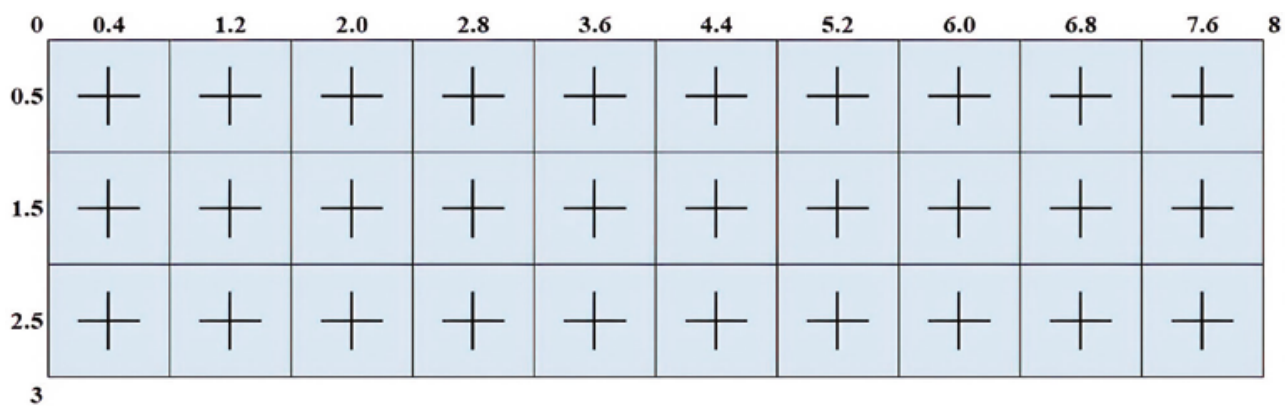

Fig. 6. Divided account areas of the surface to be illuminated 
Table 1. The Area and Lighting Parameters

\begin{tabular}{|c|c|c|c|}
\hline Number of lanes & 1 & Lighting class & M2 \\
\hline Strip width $(\mathrm{m})$ & 3 & Console angle (degree) & 0 \\
\hline Total width $(\mathrm{m})$ & 3 & Luminaire angle (degree) & 15 \\
\hline Road surface class & $R 1$ & Lamp type & LED \\
\hline$Q_{o}$ & 0.10 & Luminaire power (W) & 18 \\
\hline Distance to illumination & 0 & Luminous flux (lm) & 1825 \\
\hline Illumination height from ground $(\mathrm{m})$ & 5 & $\begin{array}{c}\text { Maintenance factor } \\
\text { (once a year) }\end{array}$ & 0.88 \\
\hline
\end{tabular}

to be calculated for lighting is selected. According to the observer, who is positioned to stand in the middle of the area, point calculation has been made. Fig. 6 shows the entire illuminated field of the pantograph with the calculated areas of the illuminated surface separated. The LED luminaire mounted in the wagon illuminates the pantograph at a right angle. Calculations were made according to the total illuminance levels and total luminance values coming from all luminaires [7-10, 50-52].

\subsection{Features of The Area Lighting}

The road surface class is $R 1$. Additionally, $\mathrm{Q}_{0}=0.10$, and the distance of the luminaire is $5 \mathrm{~m}$. The maintenance factor of the luminaire is 0.91 , and all calculated luminance values are corrected. The ratio of the lowest luminance value to mean luminance value is greater than 0.4 in the calculations for area lighting, ensuring that the rate of the lowest luminance value to the highest at the latitude coordinate of the observer is greater than 0.7. The illuminance levels, luminance value, and uniformities of the area are in accordance with relevant standards. Luminaires were established in single from

Table 2. Optimal Parameters of The Illuminated Surface for The Camera

\begin{tabular}{|c|c|}
\hline Observer location (m) & $\mathbf{1 . 5 0}$ \\
\hline$L_{\text {average }}$ & 1.51 \\
\hline$U_{o}$ & 0.77 \\
\hline$U_{l}$ & 0.82 \\
\hline$T I \%$ & 3.00 \\
\hline$E_{\text {average }}$ & 29.06 \\
\hline$E_{\min }$ & 20.92 \\
\hline$E_{\max }$ & 35.84 \\
\hline$U_{o a}$ & 0.72 \\
\hline$U_{l a}$ & 0.58 \\
\hline
\end{tabular}

to the axis of the area and at a distance of $5 \mathrm{~m}$. This study simulation was performed accordingly with LED luminaires [48, 49, 53-55]. Table 1 shows the area and lighting parameters.

\subsection{Simulation Study}

The main purpose of the new studies is to reach the most economical results that provide adequate visibility conditions. In the new study on area (zonal) lighting, classifications are taken into consideration in the various scenarios' conditions. The most correct reference to area lighting is international standards. For this reason, simulation is adapted to CIE standards. According to CIE140, the luminance values, average luminance level, average and longitudinal uniformity values of all points were calculated for the observers.

Luminaries used in area lighting should be selected taking into account the glare level, the luminance level of the area, uniformity, and economy, and they should be determined in consequence of computer calculations according to the luminance method.

It is a simulation program written with Visual $\mathrm{Ba}$ sic. Various options are available for area parameters in the simulation program. For the lighting parameters are selected such characteristics as distance to the luminaire, height of the luminaire, distance of the luminaire from the road, console angle, IP protection class, pollution rate, cleaning period, and maintenance factor for the pole or suspended lighting installation. For the luminaire parameters (the name, angle of the luminaire (angle relative to the road), power of the lamp used, lifetime, luminous flux, ballast power, and new lamps) can be added into this simulation under the database process at any time. It is possible to add any type of lamp into the simulation [48, 49, 53-61]. The result of this simulation is a simple and correct calculation. 
Table 3. The Illuminance Levels for The Camera

\begin{tabular}{|c|c|c|c|c|c|c|c|c|c|c|}
\hline \multicolumn{10}{|c|}{$\boldsymbol{E}_{\text {min }}=\mathbf{2 0 . 9 2} \mathrm{Ix} \boldsymbol{E}_{\boldsymbol{m a x}}=\mathbf{3 5 . 8 4} \mathrm{Ix} \boldsymbol{E}_{\text {average }}=\mathbf{2 9 . 0 6} \mathrm{Ix} \boldsymbol{U}_{\boldsymbol{~ o a ~}}=\mathbf{0 . 7 2} \boldsymbol{U}_{\text {la }}=\mathbf{0 . 5 8}$} \\
\hline $\mathbf{m} / \mathbf{m}$ & $\mathbf{0 . 3 5}$ & $\mathbf{1 . 0 5}$ & $\mathbf{1 . 7 5}$ & $\mathbf{2 . 4 5}$ & $\mathbf{3 . 1 5}$ & $\mathbf{3 . 8 5}$ & $\mathbf{4 . 5 5}$ & $\mathbf{5 . 2 5}$ & $\mathbf{5 . 9 5}$ & $\mathbf{6 . 6 5}$ \\
\hline $\mathbf{0 . 5 0}$ & 25.38 & 20.91 & 27.30 & 24.88 & 25.84 & 25.84 & 24.88 & 27.30 & 20.91 & 25.38 \\
\hline $\mathbf{1 . 5 0}$ & 30.29 & 30.71 & 34.56 & 35.83 & 34.42 & 34.43 & 35.83 & 34.56 & 30.71 & 30.30 \\
\hline $\mathbf{2 . 5 0}$ & 27.68 & 27065 & 28.54 & 32.03 & 29.74 & 29.74 & 32.03 & 28.54 & 27.66 & 27.69 \\
\hline
\end{tabular}

Table 4. The Luminance Values for The Camera

\begin{tabular}{|c|c|c|c|c|c|c|c|c|c|c|}
\hline \multicolumn{10}{|c|}{ Observer: $\boldsymbol{L}_{\text {average }}=\mathbf{1 . 5 1} \mathbf{c d} / \mathbf{m}^{2}, \boldsymbol{U}_{\boldsymbol{o}}=\mathbf{0 . 7 7}, \boldsymbol{U}_{\boldsymbol{⿰}}=\mathbf{0 . 8 2}, \boldsymbol{T I}=\mathbf{3 . 0} \%$} \\
\hline $\mathbf{m} / \mathbf{m}$ & $\mathbf{0 . 3 5}$ & $\mathbf{1 . 0 5}$ & $\mathbf{1 . 7 5}$ & $\mathbf{2 . 4 5}$ & $\mathbf{3 . 1 5}$ & $\mathbf{3 . 8 5}$ & $\mathbf{4 . 5 5}$ & $\mathbf{5 . 2 5}$ & $\mathbf{5 . 9 5}$ & $\mathbf{6 . 6 5}$ \\
\hline $\mathbf{0 . 5 0}$ & 1.28 & 1.15 & 1.33 & 1.30 & 1.41 & 1.44 & 1.36 & 1,39 & 1.17 & 1.29 \\
\hline $\mathbf{1 . 5 0}$ & 1.61 & 1.65 & 1.78 & 1.91 & 1.97 & 1.93 & 1.96 & 1,81 & 1.66 & 1.62 \\
\hline $\mathbf{2 . 5 0}$ & 1.29 & 1.29 & 1.34 & 1.50 & 1.50 & 1.50 & 1.57 & 1,38 & 1.33 & 1.32 \\
\hline
\end{tabular}

\section{LIGHTING APPLICATION}

In this study, a 1-lane area that is suitable for CIE140-2000 and 2019 (2 ${ }^{\text {nd }}$ edition) area lighting calculations has been investigated in the simulated environment. Calculations were made at an angle of $15^{\circ}$ for $18 \mathrm{~W}$ LED luminaire. While $L_{\text {average }}=1.50 \mathrm{~cd} / \mathrm{m}^{2}$, this corresponds to CIE140 2000 and 2019 ( $2^{\text {nd }}$ edition) road lighting calculations for $M 2$. If $L_{\text {average }}=1.50 \mathrm{~cd} / \mathrm{m}^{2}$ is less, then the lighting is not suitable for CIE140-2000 and 2019 ( $2^{\text {nd }}$ edition). To increase the camera vision, $18 \mathrm{~W}$ LED luminaire was used in the lighting. This LED light was able to meet the normalized parameters according to CIE140-2019. As for the illuminance level and luminance values, the $18 \mathrm{~W}$ LED luminaire increased visibility. The optimal parameters of the illuminated surface for the camera are shown in Table 2.

In this study, measurement and calculation were made using simulation at 30 points selected in horizontal and vertical positions. Table 3 shows the illuminance levels for the camera, and Table 4 shows the luminance values for the camera.

\section{RESULTS}

Proper design of the lighting installation is of great importance for both driving and safety. The main purpose of new studies investigating the pantograph catenary interaction in electric rail systems is the detection of malfunctions.

The main subject of this study is to increase the visibility of cameras used in railway systems. Supplying optimal lighting is to refine fault detection.
For this purpose, a camera and a LED luminaire $18 \mathrm{~W}$ were installed on a wagon, which is one of the electric railway system elements. This allows you to see more clearly the failures that occur during the movement of the electric train.

There is $5 \mathrm{~m}$ between the LED luminaire and the pantograph catenary contact point. The measurements were made while the wagon was moving. For lighting criteria, it was treated as a road vehicle moving under normal road conditions. The simulation used was adapted to CIE140-2019 ( $2^{\text {nd }}$ edition) standards. According to CIE140, the luminance values, average illuminance level, average and longitudinal uniformity values of all points were calculated for the observers. The data of the luminaire used has been entered into the simulation database. The results were analysed for the good vision of the camera recording on the moving wagon.

Lighting conditions are very important in such experimental studies. Because the visual ability of the camera on the wagon affects the success of the applied mathematical methods. For example, in a mathematical method that detects $85 \%$ malfunction, fault detection can be $99 \%$ if the camera records more clearly. In this respect, the lighting of the test environment is one of the most parameters affecting the failure detection success. As in this study, special solutions should be analysed in simulated lighting environments.

\section{ACKNOWLEDGEMENT}

This work has been supported by the Scientific and Technological Research Council of Turkey (TUBITAK) under Grant EEEAG-118E322. (EEE- 
AG: Electrical Electronics Engineering Research Group).

\section{REFERENCES:}

1. Yaman O., Pantograf-Katener Sistemlerinde Görüntü İşleme Tabanli Temassız İzleme Yöntemlerinin Geliştirilmesi, Yüksek Lisans Tezi, Firat Üniversitesi, Fen Bilimleri Enstitüsü, 2014, p. 122.

2. Karaköse E., Rayli Sistemlerde Pantograf-Katener Sisteminin Modellenmesi, Simülasyonu ve Ariza Teşhis Yöntemlerinin Geliştirilmesi, Yüksek Lisans Tezi, Firat Üniversitesi, Fen Bilimleri Enstitüsü, 2014, p. 190.

3. Aydın I., Karaköse E., Karaköse M., Gençoğlu M.T., Akın E. A new computer vision approach for active pantograph control, 2013 International Conference on Innovations in Intelligent Systems and Applications, 2013, pp. 1-5.

4. Karakose E., Gençoğlu M.T., Karakose M., Yaman O., Aydin, I., Akin E. (2018) A new arc detection method based on fuzzy logic using S-transform for pantograph-catenary systems, Journal of Intelligent Manufacturing, 2018. V29, \#4, pp. 839-856.

5. Parlakyıldız S., Gençoğlu M.T., Cengiz M.S. 2018. Development of Rail Systems from Past to Present. International Conference on Multidisciplinary, Science, Engineering and Technology (2018 Dubai, BAE)

6. Cengiz Ç., Yapıc1, İ., Cengiz M.S. 2018. Fourier Analysis in Rail Systems. International Conference on Multidisciplinary, Science, Engineering and Technology (2018 Dubai, BAE).

7. Cengiz M.S., The Relationship Between Maintenance Factor and Lighting Level in Tunnel Lighting, Light \& Engineering, 2019. V27, \#3, pp. 75-84.

8. Cengiz M.S., Cengiz, Ç., Numerical Analysis of Tunnel LED Lighting Maintenance Factor, IIUM Engineering Journal. 2018. V19, \#2, pp. 154-163.

9. Efe S.B., Varhan D. Interior Lighting of A Historical Building By Using LED Illuminators: A Case Study Of Fatih Paşa Mosque, Light \& Engineering, 2020. V28, \#4, pp. 77-83.

10. Cengiz M.S., A Simulation and Design Study for Interior Zone Luminance in Tunnel Lighting, Light \& Engineering, 2019. V27, \#2, pp. 42-51.

11. Sabato, A. and Niezrecki, C. Feasibility of Digital Image Correlation for railroad tie inspection and ballast support assessment. Measurement, 2017. V103, pp. 93-105.

12. Manikandan, R., Balasubramanian, M. and Palanivel, S. Machine Vision Based Missing Fastener Detection In Rail Track Images Using Svm Classifier. In- ternational Journal on Smart Sensing and Intelligent Systems, 2017. V10, \#4, pp. 574-589.

13. Biswas R., Khan R.A., Islam S. and Uddin J. A Novel Approach to Detect and Classify the Defective of Missing Rail Anchors in Real-time. International Journal of Emerging Technology and Advanced Engineering, 2016. V6, \#12, pp. 270-276.

14. Liu J., Li B., Xiong Y., He B., and Li L., 2015. Integrating the symmetry image and improved sparse representation for railway fastener classification and defect recognition. Mathematical Problems in Engineering, 2015.

15. Gibert X., Patel V.M. and Chellappa R. Robust fastener detection for autonomous visual railway track inspection. IEEE Winter Conference on Applications of Computer Vision (WACV), 2015. pp. 694-701.

16. Gibert X., Patel V.M., and Chellappa R. Deep multitask learning for railway track inspection. IEEE Transactions on Intelligent Transportation Systems, 2017. V18, \#1, pp. 153-164.

17. Fan H., Cosman P.C., Hou Y. and Li B. HighSpeed Railway Fastener Detection Based on a Line Local Binary Pattern. IEEE Signal Processing Letters, 2018. V25, \#6, pp. 788-792.

18. Yuan X., Liu B. and Chen H. Algorithm and program design for fastener locating and detection using wavelet transformation and template matching. IEEE17th International Conference on Communication Technology (ICCT), 2017. pp. 1116-1121.

19. Liu J. and Li B. Railway fastener defects recognition algorithm based on computer vision. International Conference on Electronic Science and Automation Control (ESAC2015), 2015. pp. 285-288.

20. Trinh H., Haas N., Ying Li., Otto C., Pankanti S. Enhanced rail component detection and consolidation for rail track inspection, IEEE Workshop on Applications of Computer Vision (WACV), 2012. pp. 289-295.

21. Feng H., Jiang Z., Xie F., Yang P., Shi J., Chen L. Automatic fastener classification and defect detection in vision-based railway inspection systems. IEEE Transactions on Instrumentation and Measurement, 2014. V63, \#4, pp. 877-888.

22. Babenko P. Visual inspection of railroad tracks, Doctoral dissertation, University of Central Florida Orlando, Florida, 2009.

23. Ying L., Trinh T., Haas N., Otto C., Pankanti S. Rail Component Detection, Optimization, and Assessment for Automatic Rail Track Inspection, IEEE Transactions on Intelligent Transportation Systems, 2014. V15, pp. 760-770.

24. Sawadısavı S.V. Development of Machine-Vision Technology for Inspection of Railroad Track, Graduate 
College of the University of Illinois at Urbana-Champaign, 2010.

25. Mao Q., Cui H., Hu Q. and Ren X. A rigorous fastener inspection approach for high-speed railway from structured light sensors. ISPRS Journal of Photogrammetry and Remote Sensing, 2017.

26. Aytekin Ç., Rezaeitabar Y., Dogru S. and Ulusoy I. Railway fastener inspection by real-time machine vision. IEEE Transactions on Systems, Man, and Cybernetics: Systems, 2015. V45, \#7, pp. 1101-1107.

27. Santur Y., Karaköse M. and Akin, E. A new rail inspection method based on deep learning using laser cameras. International Artificial Intelligence and Data Processing Symposium (IDAP), 2017. pp. 1-6.

28. Santur Y., Karaköse M. and Akin E. Big data framework for rail inspection. International Artificial Intelligence and Data Processing Symposium (IDAP), 2017. pp. 1-4.

29. Wang C., Li Y., Ma Z., Zeng J., Jin T. and Liu H. Distortion Rectifying for Dynamically Measuring Rail Profile Based on Self-Calibration of Multiline Structured Light. IEEE Transactions on Instrumentation and Measurement, 2018.

30. Xiong Z., Li Q., Mao Q. and Zou Q.. A 3D laser profiling system for rail surface defect detection. Sensors, 2017. V17, \#8, p. 1791.

31. Yunjie Z., Xiaorong G., Lin L., Yongdong P. and Chunrong Q. Simulation of Laser Ultrasonics for Detection of Surface-Connected Rail Defects. Journal of Nondestructive Evaluation, 2017. V36, \#4, p. 70.

32. Wohlfeil J. Vision based rail track and switch recognition for self-localization of trains in a rail network. In Intelligent Vehicles Symposium (IV), 2011. pp. 1025-1030.

33. Johansson A., Pålsson B., Ekh M., Nielsen J.C., Ander M.K., Brouzoulis J. and Kassa E. Simulation of wheel-rail contact and damage in switches \& crossings. Wear, 2011. V271, \#1, pp. 472-481.

34. Palsson B. Optimisation of railway switches and crossings, Chalmers University of Technology, 2014.

35. Singh A. K., Swarup A., Agarwal A. and Singh D. Vision based rail track extraction and monitoring through drone imagery. ICT Express, 2017.

36. Li Q., Shi Z., Zhang H., Tan Y., Ren S., Dai P. and Li W. A cyberenabled visual inspection system for rail corrugation. Future Generation Computer Systems, 2018. V79, pp. 374-382.

37. Zhuang L., Wang L., Zhang Z. and Tsui K.L. Automated vision inspection of rail surface cracks: A double-layer data-driven framework. Transportation Research Part C: Emerging Technologies, 2018. V92, pp. 258-277.
38. Min Y., Xiao B., Dang J., Yue B. and Cheng T. Real time detection system for rail surface defects based on machine vision. EURASIP Journal on Image and Video Processing, 2018. V1, p. 3.

39. Biao Y. U. E. and MIN Y.Z. An Adaptive Background Adjusting Algorithm for Rail Surface Defect Image Segmentation. DEStech Transactions on Computer Science and Engineering, 2017.

40. Gan J., Li Q., Wang J. and Yu H. A Hierarchical Extractor-Based Visual Rail Surface Inspection System. IEEE Sensors Journal, 2017. V17, \#23, pp. 7935-7944.

41. Shang L., Yang Q., Wang J., Li S. and Lei W. Detection of rail surface defects based on $\mathrm{CNN}$ image recognition and classification. 20th International Conference on Advanced Communication Technology (ICACT), 2018. pp. 45-51.

42. Faghih-Roohi S., Hajizadeh S., Núñez A., Babuska R. and De Schutter B. Deep convolutional neural networks for detection of rail surface defects. International Joint Conference Neural Networks (IJCNN), 2016. pp. 2584-2589.

43. Liu Z., Wang W., Zhang X. and Jia W. Inspection of rail surface defects based on image processing. International Asia Conference on Automation and Robotics Informatics in Control, 2nd, 2010. V1, pp. 472-475.

44. Dubey A., and Jaffery Z. Maximally Stable Extremal Region Marking (MSERM) based Railway Track Surface Defect Sensing, IEEE Sensors Journal, 2016.

45. Steenbergen M. and Dollevoet R. On the mechanism of squat formation on train rails-Part I: Origination, International Journal of Fatigue, 2013. V47, pp. 361-372.

46. Tastimur C., Yetis H., Karaköse M. and Akın E., Rail Defect Detection and Classification with Real Time Image Processing Technique. International Journal of Computer Science and Software Engineering (IJCSSE), V5,\#12, pp. 283-290.

47. Zheng S. Chai X. An X., Li L. Railway Track Gauge Inspection Method Based on Computer Vision, International Conference on Mechatronics and Automation (ICMA), 2012. pp. 1292-1296.

48. CIE140:2000 - Road Lighting Calculations. CIE140, International Commission on Illumination, Road Lighting Calculations, Vienna-Austria, 33 (2000).

49. CIE140:2019 Road Lighting Calculations. CIE140, International Commission on Illumination, $2^{\text {nd }}$ Edition ISBN:978-3-902842-56-5.

50. Cengiz Ç., Kaynaklı M., Gencer G., Eren M., Yapici İ., Yildirim S., Cengiz M.S., Selection Criteria and Economic Analysis of LEDs, Book of Abstracts, Imeset Int. Conf. Mult. Sci. Eng. Tech., October 27-29, 2017, Bitlis, Turkey. 
51. Gencer G., Eren M., Yildirim S., Kaynaklı M., Palta O., Cengiz M.S., Cengiz Ç., Numerical Approach to City Road Lighting Standards, Book of Abstracts, Imeset Int. Conf. Mult. Sci. Eng. Tech., October 27-29, 2017, Bitlis, Turkey.

52. Yıldırım S., Yapıcı İ., Atiç S., Eren M., Palta O., Cengiz Ç., Cengiz M.S., Yurci Y., Numerical Analysis of Productivity and Redemption Periods in LED Illimunation. Imeset Book of Abstracts, Int. Conf. Mult. Sci. Eng. Tech., 12-14 July 2017, Baku.

53. Onaygil S., TEDAŞ Genel Müdürlüğü Meslek İçi Eğitim Semineri, TEDAŞ Basımevi, Ankara, 2005, pp. 1-70.

54. Onaygil S., 2007. TEDAŞ Genel Müdürlüğü Meslek İçi Eğitim Semineri-Gölbaşı Eğitim Tesisleri, Yol aydnlatma Semineri 23-24 Ocak 2007.

55. Güler Ö. \& Onaygil S., The effect of luminance uniformity on visibility level in road lighting, Lighting Research Technology, 2002. V35, pp. 199-215.
56. Çıbuk M., Cengiz M.S. Determination of Energy Consumption According to Wireless Network Topologies in Grid-Free Lighting Systems. Light \& Engineering, 2020. V28, \#2, pp. 67-76.

57. Çıbuk M., Reducing Energy Consumption in Single-Hop and Multi-Hop Topologies of Road Lighting Communication Network, 2020. V28, \#4 pp. 91-102.

58. Efe S. B., UPFC Based Real-Time Optimization of Power Systems for Dynamic Voltage Regulation. Computer Modeling in Engineering \& Sciences, 2018. V116, \#3, pp. 391-406.

59. Efe S. B., Cebeci M. Power Flow Analysis by Artificial Neural Network. International Journal of Energy and Power Engineering, 2013. V2, \#6, pp. 204-208.

60. Cengiz, M.S. Simulation and Design Study for Interior Zone Luminance In unnel Lighting. Light \& Engineering, 2019. V27, \#2, pp. 42-51.

61. Cengiz M.S. Effects of Luminaire Angle and Illumination Topology on Illumination Parameters in Road Lighting. Light \& Engineering, 2020. V28, \#4 pp. 47-56.

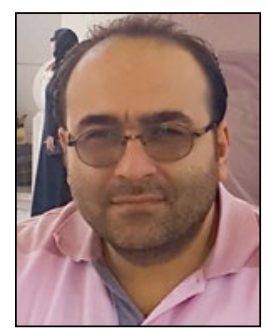

\section{Sakir Parlakyıldiz,}

M. Sc. He is a Ph.D. student in Firat University, faculty of engineering, department of electrical and electronics engineering. He currently works as a lecturer at Bitlis Eren University, Vocational school of technical sciences, department of biomedical device technologies

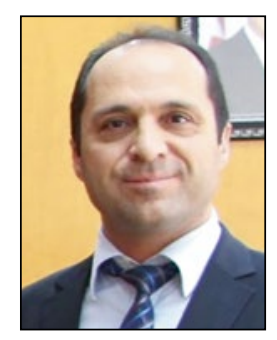

\section{Muhsin Tunay Gencoglu}

was an associate professor in 2011 and a professor in 2017 at Firat University, Department of Electrical and Electronics Engineering. His area of interest is electrical facilities and power supply systems

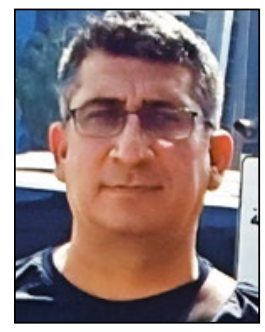

\section{Mehmet Sait Cengiz,}

Ph.D. He had got his Master Degree in 2011 and Ph.D. in 2016. His specialization area is electrical-electronics engineering (light). He still works in the field of applied lighting 